\title{
Prospective Multicenter Surveillance Study of Surgical Site Infection after Spinal Surgery in Korea : A Prelimi- nary Study
}

\author{
Tae Seok Jeong, M.D., Gi Taek Yee, M.D., Ph.D. \\ Department of Neurosurgery, Gil Medical Center, Gachon University College of Medicine, Incheon, Korea
}

Objective : This study aimed to investigate the rates, types, and risk factors of surgical site infection (SSI) following spinal surgery using data from a Korean SSI surveillance system that included diagnoses made by surgeons.

Methods : This was a prospective observational study of patients who underwent spinal surgeries at 42 hospitals in South Korea from January 2017 to December 2017. The procedures included spinal fusion, laminectomy, discectomy, and corpectomy. Univariate and multivariate logistic regression analyses were performed.

Results : Of the 3080 cases included, 30 showed infection, and the overall SSI rate was 1.0\% (an incidence of 1.2\% in spinal fusion and $0.6 \%$ in laminectomy). Deep incisional infections were the most common type of SSIs (46.7\%). Gram-positive bacteria caused $80 \%$ of the infections, and coagulase-negative staphylococci, including Staphylococcus epidermidis, accounted for $58 \%$ of the grampositive bacteria. A longer preoperative hospital stay was significantly associated with the incidence of SSI after both spinal fusion and laminectomy $(p=0.013, p<0.001)$. A combined operation also was associated with SSI after laminectomy $(p=0.032)$.

Conclusion : An SSI surveillance system is important for the accurate analysis of SSI. The incidence of SSI after spinal surgery assessed by a national surveillance system was $1.0 \%$. Additional data collection will be needed in future studies to analyze SSI in spinal surgery.

Key Words : Surgical site infection · Spine $\cdot$ Spinal fusion $\cdot$ Laminectomy $\cdot$ Risk factors.

\section{INTRODUCTION}

Surgical site infection (SSI) is the third most frequently reported nosocomial infection, accounting for $14-16 \%$ of all infections in hospitalized patients and 38\% of all infections in surgical patients ${ }^{7,15)}$. SSI is associated with substantial morbidity and mortality, a prolonged hospital stay, and increased ex- penses ${ }^{22)}$. SSIs after spinal surgery have been reported to occur in $0.7-12.0 \%$ of patients ${ }^{18)}$. The incidence of SSI after spinal surgery is influenced both by patient characteristics and preoperative or intraoperative factors. Known risk factors include advanced age, drug and alcohol abuse, smoking history, diabetes, obesity, malnutrition, immunological insufficiency, surgery for spine trauma, prolonged surgical

- Received : May 21, 2018 •Revised : July 2, 2018 •Accepted : July 21, 2018

- Address for reprints : Gi Taek Yee, M.D., Ph.D.

Department of Neurosurgery, Gil Medical Center, Gachon University College of Medicine, 21 Namdong-daero 774beon-gil, Namdong-gu, Incheon 21565, Korea Tel : +82-32-460-3304, Fax : +82-32-460-3899, E-mail : gtyee@gilhospital.com

This is an Open Access article distributed under the terms of the Creative Commons Attribution Non-Commercial License (http://creativecommons.org/licenses/by-nc/4.0) which permits unrestricted non-commercial use, distribution, and reproduction in any medium, provided the original work is properly cited. 
time, high blood loss, posterior approach, use of instrumentation, and a high volume of personnel moving through the operating room $^{2,8,12,18,19,21,23)}$.

Many efforts have been made to prevent SSI, one of which is the use of infection surveillance systems. The Korean National Healthcare-Associated Infection Surveillance System (KONIS) is operated by the Korean Centers for Disease Control and Prevention (CDC). It monitors the current status of SSI in Korea as a whole and helps develop ways to reduce the SSI rate. Hospitals of all sizes are enrolled in the KONIS system. This study aimed to investigate the rates, types, and risk factors for SSI following spinal surgery.

\section{MATERIALS AND METHODS}

This was a prospective observational study of patients who underwent spinal surgery at 42 hospitals in South Korea from January 2017 to December 2017. The spinal surgeries included spinal fusion, laminectomy, discectomy, and corpectomy. Prophylactic antibiotics were administered to all patients in accordance with the Ministry of Health guidelines. A firstgeneration cephalosporin was administered within 1 hour before skin incision and was continued for up to 48 hours after surgery. Patients who were under 18 years of age, were transferred, had a fever greater than 38 degrees within 24 hours before surgery, had an American Society of Anesthesiologists (ASA) class of 4 or higher, underwent more than two operations during their hospital stay, or underwent emergency operations were excluded from the prophylactic antibiotics guidelines. For surveillance, surgical procedures were classified using KONIS-SSI codes, referencing the 2017 electronic data interchange insurance codes. The KONIS-SSI codes for the surgical procedures in this study were spinal fusion (FUSN) and laminectomy (LAM). Table 1 shows the Health Insurance electronic data interchange codes for FUSN and
LAM. Patients were monitored for 90 days after surgery; those discharged or transferred were monitored at outpatient clinics. Patients who passed away within 48 hours after surgery or who did not have the incision site closed were excluded in this study.

\section{Participating hospital}

Hospitals meeting the following criteria were included in the study : first, the surgeon must be designated as the head of the clinic to identify and sign the SSI. Second, monitoring for SSI must be conducted periodically according to standards and methods defined by KONIS-SSI manual, and it must be agreed that KONIS-SSI steering committee confirms the accuracy of data entered by the hospital. Third, it is recommended that a diagnosis of SSI is decided through a review process by the surgeon and infection control specialist, who must complete education by KONIS-SSI steering committee at least once a year. Fourth, it is recommended that procedures and systems of medical institutions are established to share surveillance matters with the surgeon.

\section{Data}

Data were collected by the surgeon performing the surgery and nurse practitioners who had completed the KONIS-SSI steering committee course at least once a year. Data included were age, sex, duration of preoperative hospital stay, elective or emergency surgery, endoscopic procedure, combined surgery, reoperation, surgery for trauma, operation time, wound classification (clean, clean-contaminated, contaminated, or dirty $)^{3)}$, ASA classification ${ }^{1)}$, National Nosocomial Infection Surveillance-derived risk index ${ }^{10)}$, infection, and infecting microorganisms. These values were recorded on standardized worksheets specifically designed according to the guidelines in the KONIS-SSI manual.

Table 1. KONIS-SSI and EDI codes for neurosurgical procedures included in the study

\begin{tabular}{lcc}
\hline KONIS-SSI code & Type of surgery & 2017 Health Insurance EDI standard code \\
\hline FUSN & Spinal fusion & N0444, N0445, N0446, N0447, N0466, N0468, N0469, N1460, N1466, N1469, N2461, \\
& N2462, N2463, N2464, N2465, N2466, N2467, N2468, N2469, N2470 \\
LAM & Laminectomy & N0451, N0452, N0453, N1491, N1492, N1493, N1494, N1497, N1498, N1499, N2497, \\
& N2498, N2499 \\
\hline
\end{tabular}

KONIS : Korean National Healthcare-Associated Infection Surveillance System, SSI : surgical site infection, EDI : electronic data interchange, FUSN : spinal fusion, LAM : laminectomy 
Table 2. Criteria for diagnosis of SSI

\begin{tabular}{|c|c|c|c|}
\hline & Superficial incisional SSI & Deep incisional SSI & Organ/space SSI \\
\hline Duration of infection & Within 30 days after surgery & Within 90 days after surgery & Within 90 days after surgery \\
\hline Infection site & Skin or subcutaneous tissue & $\begin{array}{l}\text { Deep soft tissue (fascia and muscle } \\
\text { layers) }\end{array}$ & $\begin{array}{l}\text { Body area deeper than fascia and } \\
\text { muscle layer }\end{array}$ \\
\hline \multirow[t]{4}{*}{$\begin{array}{l}\text { Include at least one of the } \\
\text { followings }\end{array}$} & $\begin{array}{l}\text { 1. Purulent drainage from superficial } \\
\text { incision }\end{array}$ & $\begin{array}{l}\text { 1. Purulent drainage from deep incision } \\
\text { but not from organ/space }\end{array}$ & $\begin{array}{l}\text { 1. Purulent drainage from a drain that is } \\
\text { placed through a stab wound into the } \\
\text { organ/space }\end{array}$ \\
\hline & $\begin{array}{l}\text { 2. Superficial incision dehiscence or } \\
\text { opened by the surgeon and there } \\
\text { is a positive culture from superficial } \\
\text { incision site }\end{array}$ & $\begin{array}{l}\text { 2. Deep incision dehiscence or opened } \\
\text { by the surgeon and a positive culture } \\
\text { was found from deep incision site }\end{array}$ & $\begin{array}{l}\text { 2. Organisms isolated from an } \\
\text { aseptically obtained culture of fluid or } \\
\text { tissue in the organ/space }\end{array}$ \\
\hline & $\begin{array}{l}\text { 3. At least one symptom of pain or } \\
\text { tenderness, localized swelling, } \\
\text { redness, or heat, even if culture test } \\
\text { was not performed }\end{array}$ & $\begin{array}{l}\text { 3. At least one of fever }\left(>38^{\circ} \mathrm{C}\right) \text {, localized } \\
\text { pain, or tenderness, even if culture } \\
\text { test was not performed }\end{array}$ & $\begin{array}{l}\text { 3. Abscess or other evidence of infection } \\
\text { organ/space on direct examination, } \\
\text { reoperation, histopathologic or } \\
\text { radiologic examination }\end{array}$ \\
\hline & & \multicolumn{2}{|l|}{$\begin{array}{l}\text { 4. Abscess or other evidence of } \\
\text { infection of deep incision on } \\
\text { direct examination, reoperation, } \\
\text { histopathologic or radiologic } \\
\text { examination }\end{array}$} \\
\hline
\end{tabular}

SSI : surgical site infection

\section{SSI criteria and wound classification}

The criteria used to define SSI were established by the CDC in $2017^{3,4)}$. By these criteria, SSI is defined as any infection occurring within 1 month of the operation when no prosthetic material was left in the wound or within 1 year when prosthetic material remained within the operation site. Because the maximum monitoring period in this study was 90 days, SSIs for spinal fusion surgeries using prosthetic materials were defined as infections occurring within 90 days.

SSIs were classified depending on the degree of infection as follows : superficial incisional, deep incisional, and organ/ space. These categories involved skin or subcutaneous tissue at the incision, deep soft tissue (fascia and muscle layers) at the incision, or any part of the anatomy (organs or organ spaces), respectively. The diagnosis of SSI was determined when the criteria in Table 2 were met.

Wounds were classified according to the degree of contamination of a surgical wound at the time of the operation as follows : clean, clean-contaminated, contaminated, and dirty.

\section{Statistical analysis}

To compare differences in variables between the SSI and non-SSI groups, Fisher's exact test or the Wilcoxon rank sum test were used. Spearman correlation analysis was used to ex- amine the correlation between hospital scale and SSI rate. $p$ values of $<0.05$ were considered significant. Univariate and multivariate logistic regression analyses were conducted with SAS version 9.4 (SAS Institute Inc, Cary, NC, USA). The objective of the univariate analysis was to determine the risk factors linked to SSI, followed by multivariate analysis for variables with $p$-values $<0.2$.

\section{RESULTS}

\section{Population}

A total of 3080 cases (spinal fusion, 1768; laminectomy, 1312) fulfilled the inclusion criteria and were enrolled in the study from January 2017 to December 2017. Among spinal fusion cases, there were 1746 cases in the non-SSI group and 22 cases in the SSI group. The mean preoperative hospital stay was significantly longer in the SSI group than in the non-SSI group (15 vs. 41 days; $p<0.001$ ). Significant differences in ASA class were not found between the groups (Table 3). Among laminectomy cases, there were 1304 cases in the non-SSI group and eight cases in the SSI group. The mean preoperative hospital stay was significantly longer in the SSI group than in the non-SSI group (12 vs. 33 days; $p=0.004$ ) (Table 4 ). 
SSI after Spinal Surgery in Korea I Jeong TS, et al.

Table 3. General characteristics of non-SSI and SSI groups of FUSN cases

\begin{tabular}{|c|c|c|c|}
\hline & Non-SSI group $(n=1746)$ & SSI group $(n=22)$ & $p$-value \\
\hline Sex (female) & $895(51.3)$ & $14(63.6)$ & 0.248 \\
\hline Age (years) & $65(0-91)$ & $69.5(34-82)$ & 0.115 \\
\hline Endoscopic operation & $4(0.2)$ & 0 & 1 \\
\hline Emergency operation & $153(8.8)$ & $2(9.1)$ & 1 \\
\hline Trauma & $213(12.2)$ & $3(13.6)$ & 0.745 \\
\hline Combined operation & $348(19.9)$ & $3(13.6)$ & 0.597 \\
\hline Reoperation & $46(2.6)$ & 0 & 1 \\
\hline Duration of preoperative hospital stay & $15(3-459)$ & $41(10-122)$ & $<0.001^{*}$ \\
\hline \multicolumn{4}{|l|}{ Wound classification } \\
\hline Clean & $1714(98.2)$ & $21(95.5)$ & 0.197 \\
\hline Clean-contaminated & $10(0.6)$ & $1(4.6)$ & \\
\hline Contaminated & $5(0.3)$ & 0 & \\
\hline Dirty & $17(1.0)$ & 0 & \\
\hline \multicolumn{4}{|l|}{ ASA classification } \\
\hline 1 & $270(15.5)$ & $1(4.6)$ & 0.384 \\
\hline 2 & $1086(62.2)$ & $14(63.6)$ & \\
\hline 3 & 375 (21.5) & 7 (31.8) & \\
\hline 4 & $12(0.7)$ & 0 & \\
\hline 5 & $3(0.2)$ & 0 & \\
\hline Operation time (minutes) & $170(40-765)$ & $183(105-450)$ & 0.281 \\
\hline Over T-hour ${ }^{\dagger}$ & $429(24.6)$ & $7(31.8)$ & 0.433 \\
\hline
\end{tabular}

Values are presented as median value (interquartile ranges) or number (\%). * Statistically significant differences $(p$-value $<0.05)$. ${ }^{\dagger}$ The exact 75 th percentile of procedure duration in minutes. SSI : surgical site infection, FUSN : spinal fusion, ASA : American Society of Anesthesiologists

Table 4. General characteristics of non-SSI and SSI groups of LAM cases

\begin{tabular}{|c|c|c|c|}
\hline & Non-SSI group $(n=1304)$ & SSI group $(n=8)$ & $p$-value \\
\hline Sex (female) & $610(46.8)$ & $4(50.0)$ & 1 \\
\hline Age (years) & $61(6-98)$ & $70(26-74)$ & 0.404 \\
\hline Endoscopic operation & $63(4.8)$ & 0 & 1 \\
\hline Emergency operation & $132(10.1)$ & $1(12.5)$ & 0.576 \\
\hline Trauma & $36(2.8)$ & 0 & 1 \\
\hline Combined operation & $25(1.9)$ & $1(12.5)$ & 0.148 \\
\hline Reoperation & $24(1.8)$ & $1(12.5)$ & 0.143 \\
\hline Duration of preoperative hospital stay & $12(2-121)$ & $33(7-83)$ & $0.004^{*}$ \\
\hline \multicolumn{4}{|l|}{ Wound classification } \\
\hline Clean & 1272 (97.6) & $7(87.5)$ & $0.046^{*}$ \\
\hline Clean-contaminated & $5(0.4)$ & $1(12.5)$ & \\
\hline Contaminated & $9(0.7)$ & 0 & \\
\hline Dirty & $18(1.4)$ & 0 & \\
\hline \multicolumn{4}{|l|}{ ASA classification } \\
\hline 1 & $321(24.6)$ & 0 & 0.253 \\
\hline 2 & $753(57.8)$ & $6(75.0)$ & \\
\hline 3 & $222(17.0)$ & $2(25.0)$ & \\
\hline 4 & $8(0.6)$ & 0 & \\
\hline 5 & 0 & 0 & \\
\hline Operation time (minutes) & $115(30-790)$ & $149(55-515)$ & 0.333 \\
\hline Over T-hour ${ }^{\dagger}$ & $317(24.3)$ & $2(25.0)$ & 1 \\
\hline
\end{tabular}

Values are presented as median value (interquartile ranges) or number (\%). * Statistically significant differences $(p$-value $<0.05)$. ${ }^{\dagger}$ The exact 75 th percentile of procedure duration in minutes. SSI : surgical site infection, LAM : laminectomy, ASA : American Society of Anesthesiologists 


\section{Surgical procedures}

For the variables of endoscopic, emergency, combined, reoperation, and trauma, no significant differences were found between the two SSI groups for either spinal fusion or laminectomy. Additionally, operation time and over T-hour (the exact 75th percentile of the procedure duration in minutes) were not different between the two SSI groups for either spinal fusion or laminectomy. However, there was a significant difference in wound class between both SSI groups for laminectomy $(p=0.046)$ (Table 4$)$.

\section{SSI incidence}

We investigated the SSI rate by the National Nosocomial Infection Surveillance risk index category. For spinal fusion, the SSI rate was $0.9 \%$ for risk index $0,1.9 \%$ for risk index 1 , and $1.0 \%$ for risk index 2 . The overall SSI rate for spinal fusion was $1.2 \%$. For laminectomy, the SSI rate was $0.5 \%$ for risk index 0 and $0.9 \%$ for risk index 1 ; no SSI occurred in patients with risk index 2 or 3. The overall SSI rate for laminectomy was $0.6 \%$ (Table 5). In spinal fusion cases, deep incisional infections were the most common, occurring in 12 out of 22 cases. Among laminectomy cases, although only eight infections occurred, superficial incisional infections were the most common (Table 6). The overall SSI rates for spinal surgery varied according to hospital size; however, the correlation was not significant ( $p=0.333$, Table 7$)$. Of all causative organisms, gram-positive bacteria accounted for $77 \%$ (10/13) in spinal fusion and $100 \%(2 / 2)$ in laminectomy, and S. epidermidis was the most common (31\%) bacteria (Fig. 1). Identification rates of bacteria were 59\% (13/22) in spinal fusion and 25\% (2/8) in laminectomy. The overall identification rate of bacteria were $50 \%(15 / 30)$.

\section{SSI risk factors}

Univariate and multivariate analyses were performed to identify risk factors for SSI. On univariate analyses of spinal fusion, the $p$-values for age and preoperative hospital stay duration were $<0.2$, and in a multivariate analysis of both vari-

Table 5. Pooled mean and key percentiles of the distribution of SSI rates by risk index

\begin{tabular}{|c|c|c|c|c|c|}
\hline KONIS-SSI code & Risk Index & $\begin{array}{c}\text { Number of participating } \\
\text { hospitals }\end{array}$ & $\begin{array}{l}\text { Number of } \\
\text { operations }\end{array}$ & Number of infections & Infection rate (\%) \\
\hline \multirow[t]{5}{*}{ FUSN } & 0 & 29 & 1025 & 9 & 0.9 \\
\hline & 1 & 28 & 637 & 12 & 1.9 \\
\hline & 2 & 21 & 100 & 1 & 1 \\
\hline & 3 & 4 & 6 & 0 & 0 \\
\hline & Total & 30 & 1768 & 22 & 1.2 \\
\hline \multirow[t]{5}{*}{ LAM } & 0 & 24 & 813 & 4 & 0.5 \\
\hline & 1 & 24 & 424 & 4 & 0.9 \\
\hline & 2 & 16 & 71 & 0 & 0 \\
\hline & 3 & 2 & 4 & 0 & 0 \\
\hline & Total & 25 & 1312 & 8 & 0.6 \\
\hline
\end{tabular}

KONIS : Korean National Healthcare-associated Infections Surveillance System, SSI : surgical site infection, FUSN : spinal fusion, LAM : laminectomy

Table 6. Type of SSIs according to operative procedure

\begin{tabular}{lcccccc}
\hline KONIS-SSI code & Type of surgery & $\begin{array}{c}\text { Number of } \\
\text { operations }\end{array}$ & $\begin{array}{c}\text { Number of } \\
\text { infections }\end{array}$ & $\begin{array}{c}\text { Superficial } \\
\text { incisional } \\
\text { infections }\end{array}$ & $\begin{array}{c}\text { Deep incisional } \\
\text { infections }\end{array}$ & $\begin{array}{c}\text { Organ/space } \\
\text { infections }\end{array}$ \\
\hline FUSN & Spinal fusion & 1768 & 22 & 4 & 12 & 6 \\
LAM & Laminectomy & 1312 & 8 & 4 & 2 & 14 \\
\hline Total & & 3080 & 30 & 8 & 8 \\
\hline
\end{tabular}

KONIS : Korean National Healthcare-associated Infections Surveillance System, SSI : surgical site infection, FUSN : spinal fusion, LAM : laminectomy 
Table 7. SSI rate by hospital size in spinal surgery

\begin{tabular}{|c|c|c|c|c|c|c|}
\hline Number of beds & $\begin{array}{l}\text { Number of } \\
\text { operations }\end{array}$ & $\begin{array}{l}\text { Number of } \\
\text { infections }\end{array}$ & Infection rate (\%) & $\begin{array}{l}\text { Superficial } \\
\text { incisional } \\
\text { infections }\end{array}$ & $\begin{array}{l}\text { Deep incisional } \\
\text { infections }\end{array}$ & $\begin{array}{c}\text { Organ/space } \\
\text { infections }\end{array}$ \\
\hline$\leq 199$ & 11 & 0 & 0 & 0 & 0 & 0 \\
\hline $200-299$ & 336 & 3 & 0.89 & 2 & 0 & 1 \\
\hline $300-499$ & 118 & 0 & 0 & 0 & 0 & 0 \\
\hline $500-749$ & 902 & 13 & 1.44 & 3 & 3 & 7 \\
\hline $750-899$ & 1115 & 11 & 0.99 & 3 & 8 & 0 \\
\hline $900-999$ & 143 & 2 & 1.4 & 0 & 2 & 0 \\
\hline$\geq 1000$ & 455 & 1 & 0.22 & 0 & 1 & 0 \\
\hline Total & 3080 & 30 & 0.97 & 8 & 14 & 8 \\
\hline
\end{tabular}

SSI : surgical site infection

FUSN

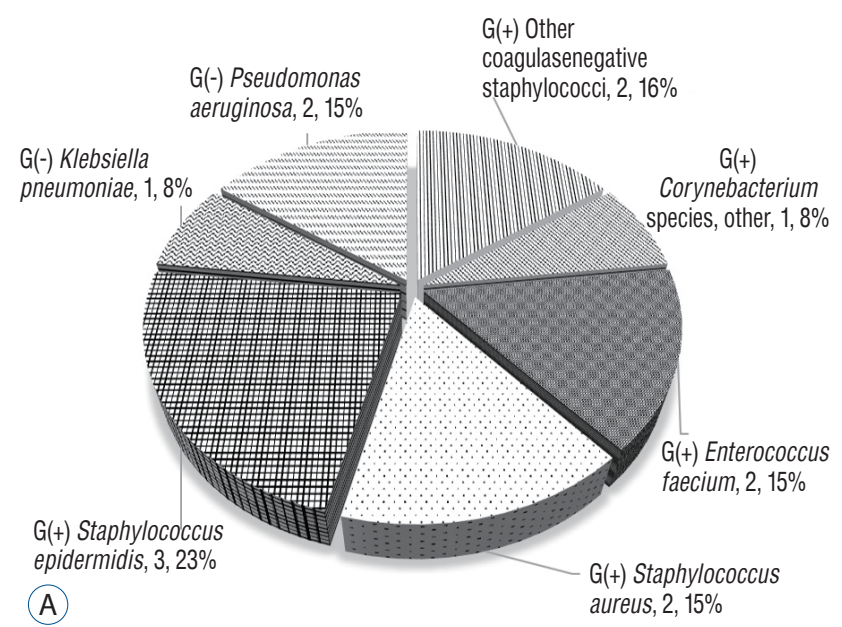

LAM

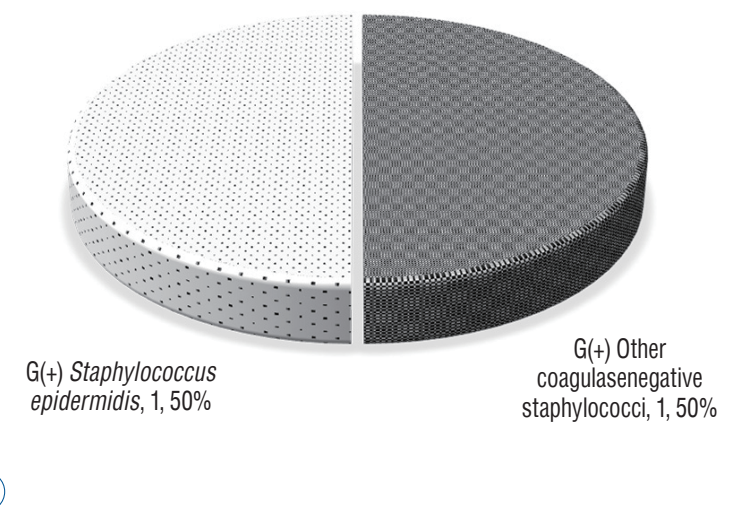

Fig. 1. Microorganisms identifvied in surgical site infections. A : Spinal fusion (FUSN), B : Laminectomy (LAM). FUSN : spinal fusion, LAM : laminectomy.

ables, only preoperative hospital stay was significantly associated with SSI incidence ( $p=0.013$, Table 8 ). On univariate analyses of laminectomy, the $p$-values for combined operation, reoperation, duration of preoperative hospital stay, and operation time were $<0.2$, and in a multivariate analysis of these four variables, combined operation and preoperative hospital stay were significantly associated with SSI incidence $(p=0.032$ and $p<0.001$, Table 9 ).

\section{DISCUSSION}

The importance of infection surveillance was acknowledged more than 40 years ago by the CDC and the Joint Commis- sion on Accreditation of Hospitals and has proven effective in preventing SSIs ${ }^{5,6}$. The Study on the Efficacy of Nosocomial Infection Control, which investigated whether a surveillance program could reduce the infection rate, concluded based on U.S. data that SSIs can be reduced by up to $32 \%$ if the following four conditions are met : 1) surveillance is continuous; 2) management efforts are aggressive; 3 ) infection control personnel are qualified; and 4) feedback on the infection rate is provided to the surgeon, especially for $\mathrm{SSI}^{11)}$. Therefore, continuous SSI surveillance and feedback on the surveillance results are important for the prevention of SSI.

In Korea, a nationwide surveillance system for SSI was first applied to orthopedic artificial joint surgery in 2006. However, because surgeons' participation in the infection surveil- 
Table 8. Univariate and multivariate analysis of factors influencing SSI in FUSN

\begin{tabular}{|c|c|c|c|c|c|c|}
\hline & \multicolumn{3}{|c|}{ Univariate } & \multicolumn{3}{|c|}{ Multivariate } \\
\hline & OR & $95 \% \mathrm{Cl}$ & $p$-value & Adjusted OR & $95 \% \mathrm{Cl}$ & $p$-value \\
\hline Sex (female vs. male) & 1.66 & $0.70,3.99$ & 0.253 & & & \\
\hline Age & 1.03 & $0.99,1.07$ & $0.178^{*}$ & 1.03 & $0.98,1.07$ & 0.222 \\
\hline Endoscopic OP (yes vs. no) & $<0.001$ & $<0.001,>999.999$ & 0.992 & & & \\
\hline Emergency OP (yes vs. no) & 1.04 & $0.24,4.50$ & 0.956 & & & \\
\hline Trauma (yes vs. no) & 1.14 & $0.33,3.87$ & 0.838 & & & \\
\hline Combined OP (yes vs. no) & 0.63 & $0.19,2.16$ & 0.466 & & & \\
\hline Reoperation (yes vs. no) & $<0.001$ & $<0.001,>999.999$ & 0.982 & & & \\
\hline Duration of preoperative hospital stay & 1.01 & $1.00,1.03$ & $0.007^{*}$ & 1.02 & $1.00,1.03$ & $0.013^{\dagger}$ \\
\hline $\begin{array}{l}\text { Wound classification (contaminated and dirty } \\
\text { vs. clean and clean-contaminated) }\end{array}$ & $<0.001$ & $<0.001,>999.999$ & 0.988 & & & \\
\hline ASA classification (ASA 1, 2 vs. ASA 3, 4, 5) & 1.62 & $0.66,4.01$ & 0.294 & & & \\
\hline Operation time & 1 & $1.00,1.01$ & 0.242 & & & \\
\hline Over T-hour ${ }^{\ddagger}$ & 1.43 & $0.58,3.54$ & 0.435 & & & \\
\hline
\end{tabular}

${ }^{*} p$-value $<0.2{ }^{~}{ }^{\dagger}$ Statistically significant differences $(p$-value $<0.05) .{ }^{\ddagger}$ The exact 75 th percentile of procedure duration in minutes. SSI : surgical site infection, FUSN : spinal fusion, OR : odds ratio, Cl : confidence interval, OP : operation, ASA : American Society of Anesthesiologists

Table 9. Univariate and multivariate analysis of factors influencing SSI in LAM

\begin{tabular}{|c|c|c|c|c|c|c|}
\hline & \multicolumn{3}{|c|}{ Univariate } & \multicolumn{3}{|c|}{ Multivariate } \\
\hline & OR & $95 \% \mathrm{Cl}$ & $p$-value & Adjusted OR & $95 \% \mathrm{Cl}$ & $p$-value \\
\hline Sex (female vs. male) & 1.14 & $0.28,4.57$ & 0.856 & & & \\
\hline Age & 1.02 & $0.97,1.07$ & 0.557 & & & \\
\hline Endoscopic OP (yes vs. no) & $<0.001$ & $<0.001,>999.999$ & 0.978 & & & \\
\hline Emergency OP (yes vs. no) & 1.27 & $0.16,10.39$ & 0.824 & & & \\
\hline Trauma (yes vs. no) & $<0.001$ & $<0.001,>999.999$ & 0.983 & & & \\
\hline Combined OP (yes vs. no) & 7.31 & $0.87,61.65$ & $0.068^{*}$ & 14.75 & $1.26,172.84$ & $0.032^{\dagger}$ \\
\hline Reoperation (yes vs. no) & 7.62 & $0.90,64.36$ & $0.062^{*}$ & 4.17 & $0.40,43.90$ & 0.235 \\
\hline Duration of preoperative hospital stay & 1.05 & $1.03,1.08$ & $<0.001^{*}$ & 1.07 & $1.03,1.11$ & $<0.001^{\dagger}$ \\
\hline $\begin{array}{l}\text { Wound classification (contaminated and dirty } \\
\text { vs. clean and clean-contaminated) }\end{array}$ & $<0.001$ & $<0.001,>999.999$ & 0.985 & & & \\
\hline ASA classification (ASA 1, 2 vs. ASA 3, 4, 5) & 1.56 & $0.31,7.76$ & 0.589 & & & \\
\hline Operation time & 1 & $1.00,1.01$ & $0.165^{*}$ & 1.01 & $1.00,2.88$ & 0.212 \\
\hline Over T-hour ${ }^{\ddagger}$ & 1.04 & $0.21,5.17$ & 0.963 & & & \\
\hline
\end{tabular}

${ }^{*} p$-value $<0.2{ }^{\dagger}$ Statistically significant differences $(p$-value $<0.05)$. ${ }^{\ddagger}$ The exact 75 th percentile of procedure duration in minutes. SSI : surgical site infection, LAM : laminectomy, OR : odds ratio, Cl : confidence interval, OP : operation, ASA : American Society of Anesthesiologists

lance system has not been mandatory, the accuracy of SSI diagnosis and surveillance has been low. Therefore, the 2017 KONIS manual mandated the participation of surgeons. This study is the first to evaluate the results of the national survey of SSI after spinal surgery using the 2017 KONIS manual. We analyzed the incidence of SSI in spinal surgery to find possible means to prevent SSI.

In this study, gram-positive bacteria caused $80 \%$ of the infections, and coagulase-negative staphylococci including $S$. epidermidis accounted for $58 \%$ of the gram-positive bacteria. Most of the coagulase-negative staphylococci associated with clinical disease are commonly found in the skin and mucous 
membranes. S. epidermidis is the most prevalent species, accounting for approximately $60-70 \%$ of all coagulase-negative staphylococci on the skin ${ }^{9,13)}$. Typically, coagulase-negative staphylococci are considered to be less virulent than S. aureus and present as indolent rather than acute infections. Despite this, they are associated with a myriad of both communityacquired and hospital-acquired diseases. Coagulase-negative staphylococci have been implicated as the causative agents in urinary tract disease, catheter-related infections, shunt infections, pneumonia, endophthalmitis, surgical wound infections, breast abscess, osteomyelitis, and native valve endocarditis. Moreover, these infections are associated with medical devices because of their propensity to form a protective biofilm $^{13,16,17,25,26)}$. Especially in spinal fusion surgery using metallic materials such as screws and rods, the risk of infections by coagulase-negative staphylococci can be high. The single most important factor that can reduce the incidence of infections due to coagulase-negative staphylococci is strict adherence to hand washing, both before and after examining patients. A meticulous surgical technique is paramount to limit intraoperative bacterial contamination, particularly in procedures where foreign bodies are being introduced. Strict attention to technique when inserting lines and catheters may also contribute to an overall reduction in infection rates ${ }^{13)}$.

In our study, the duration of the preoperative hospital stay was found to be a common risk factor in both the spinal fusion and laminectomy categories. The duration of the preoperative hospital stay is lengthened by patients' poor general condition, medical history such as diabetes mellitus or hypertension, infection status such as pneumonia, urinary tract infection, and other complications in the case of trauma. These conditions can increase the risk of SSI. However, a poor general condition is not enough to explain the duration of the preoperative hospital stay because other variables, such as ASA class and age, are also related to a poor general condition. Future research will need to analyze the causes of longer preoperative periods.

This study has several limitations. First, although the total number of patients was high, the infection group size was small, only 22 of 1746 cases. Because the number of SSIs for each variable was mostly less than 10 , the statistical power was somewhat low. There were some possibilities for lower SSI rates. The diagnostic criteria for incisional infection included pus discharge, tenderness, local edema, redness, and fever at the time of bacterium isolation from the skin incision site or subcutaneous tissue culture. However, it is possible that the surgeon did not always diagnose infection when observing some of the above symptoms, reserving the diagnosis for cases with definitive evidence of infection such as pus at the skin incision site. Additionally, in accordance with the SSI criteria used, postoperative infections were defined as those occurring within 1 year of the operation when prosthetic material remained within the operation site. The SSI rate could have been underestimated because our study analyzed preliminary data that was only 90 days in duration. In future studies, a 1-year monitoring period will be necessary. Second, the data of variables previously identified as risk factors were limited. Previously reported risk factors for SSI after spinal surgery include patient-related factors such as advanced age, smoking, diabetes, obesity, and malnutrition, as well as surgery-related factors such as placement of posterior instrumentation, fusion extending to the sacrum, multilevel surgery, the presence of a wound hematoma, pre- or perioperative steroid therapy, and increased intraoperative blood loss ${ }^{14,18,20,23,24)}$. Nationwide surveillance in this study was conducted on various types of surgeries, including general surgery, orthopedics, thoracic surgery, urology, and obstetrics and gynecology. Therefore, detailed factors focused on spinal surgery were not analyzed. Additional data collection will be needed in future studies to analyze SSI in spinal surgery.

Meanwhile, a nationwide survey on SSI in Korea has been conducted by internal medicine staff. However, there may be differences in the diagnosis of SSI as judged by surgeons and physicians. This study was the first national survey of SSI to be based on surgeons' diagnoses. Although the risk factors for SSI were not definitively identified owing to the lack of analysis of several variables, we believe that it is also very meaningful because it shows reliable results of the SSI rate in spinal surgery. In future studies, when more data are accumulated and appropriate factors are analyzed, more valuable results can be obtained to help reduce the incidence of SSI.

\section{CONCLUSION}

SSIs can cause many serious problems in spinal surgery. Identifying SSI risk factors can help reduce mortality, morbidity, and improve patient care. An SSI surveillance system is 
important for the accurate analysis of SSI. The incidence of SSI after spinal surgery assessed by a national surveillance system was $1.0 \%$, including an incidence of $1.2 \%$ for spinal fusion and $0.6 \%$ for laminectomy. The preoperative hospital stay duration was a common independent risk factor for both spinal fusion and laminectomy SSIs. A combined operation was the other risk factor in laminectomy surgeries.

\section{CONFLICTS OF INTEREST}

No potential conflict of interest relevant to this article was reported.

\section{INFORMED CONSENT}

Informed consent was obtained from all individual participants included in this study.

\section{References}

1. American Society of Anesthesiologists : ASA Physical Status Classification System. Available at : https://www.asahq.org/resources/ clinical-information/asa-physical-status-classification-system

2. Blam OG, Vaccaro AR, Vanichkachorn JS, Albert TJ, Hilibrand AS, Minnich JM, et al. : Risk factors for surgical site infection in the patient with spinal injury. Spine (Phila Pa 1976) 28 : 1475-1480, 2003

3. Centers for Disease Control and Prevention (CDC). National Healthcare Safety Network (NHSN): Surgical site infection (SSI) event. Available at : http://www.cdc.gov/nhsn/pdfs/pscmanual/9pscssicurrent. pdf

4. Centers for Disease Control and Prevention (CDC). National Healthcare Safety Network (NHSN): Surveillance Definitions for Specific Types of Infections. Available at : https://www.cdc.gov/nhsn/ pdfs/pscmanual/17pscnosinfdef_current.pdf

5. Shaw FE, Kohl KS, Lee LM, Thacker SB; Centers for Disease Control and Prevention (CDC) : Public health then and now: Celebrating 50 years of MMWR at CDC. Introduction. MMWR Suppl 60 : 2-6, 2011

6. Dixon RE; Centers for Disease Control and Prevention (CDC) : Control of health-care-associated infections, 1961-2011. MMWR Suppl 60 : 5863,2011

7. Emori TG, Gaynes RP : An overview of nosocomial infections, including the role of the microbiology laboratory. Clin Microbiol Rev 6 : 428442, 1993

8. Fang A, Hu SS, Endres N, Bradford DS : Risk factors for infection after spinal surgery. Spine (Phila Pa 1976) 30 : 1460-1465, 2005

9. Favre B, Hugonnet S, Correa L, Sax H, Rohner P, Pittet D : Nosocomial bacteremia: clinical significance of a single blood culture positive for coagulase-negative staphylococci. Infect Control Hosp Epidemiol 26 : 697-702, 2005

10. Gaynes RP, Culver DH, Horan TC, Edwards JR, Richards C, Tolson JS : Surgical site infection (SSI) rates in the United States, 1992-1998: the National Nosocomial Infections Surveillance System basic SSI risk index. Clin Infect Dis 33 Suppl 2 : S69-S77, 2001

11. Haley RW, Culver DH, White JW, Morgan WM, Emori TG, Munn VP, et al. : The efficacy of infection surveillance and control programs in preventing nosocomial infections in US hospitals. Am J Epidemiol 121 : 182-205, 1985

12. Jeong SJ, Choi SW, Youm JY, Kim HW, Ha HG, Yi JS : Microbiology and epidemiology of infectious spinal disease. J Korean Neurosurg Soc $56: 21-27,2014$

13. John Jr JF, Davidson R, Low DE : Staphylococcus epidermidis and other coagulase-negative staphylococci. Available at : http:// www.antimicrobe.org/new/b234.asp\#t11

14. Klein JD, Hey LA, Yu CS, Klein BB, Coufal FJ, Young EP, et al. : Perioperative nutrition and postoperative complications in patients undergoing spinal surgery. Spine (Phila Pa 1976) 21 : 2676-2682, 1996

15. Mangram AJ, Horan TC, Pearson ML, Silver LC, Jarvis WR; The Hospital Infection Control Practices Advisory Committee : Guideline for prevention of surgical site infection, 1999. Am J Infect Control 27 : 97-134, 1999

16. Marculescu CE, Berbari EF, Cockerill FR 3rd, Osmon DR : Unusual aerobic and anaerobic bacteria associated with prosthetic joint infections. Clin Orthop Relat Res 451 : 55-63, 2006

17. Moazzez A, Kelso RL, Towfigh S, Sohn H, Berne TV, Mason RJ : Breast abscess bacteriologic features in the era of community-acquired methicillin-resistant Staphylococcus aureus epidemics. Arch Surg 142 : 881 884, 2007

18. Olsen MA, Mayfield J, Lauryssen C, Polish LB, Jones M, Vest J, et al. : Risk factors for surgical site infection in spinal surgery. J Neurosurg 98(2 Suppl) : 149-155, 2003

19. Olsen MA, Nepple JJ, Riew KD, Lenke LG, Bridwell KH, Mayfield J, et al. : Risk factors for surgical site infection following orthopaedic spinal operations. J Bone Joint Surg Am 90 : 62-69, 2008

20. Perry JW, Montgomerie JZ, Swank S, Gilmore DS, Maeder K : Wound infections following spinal fusion with posterior segmental spinal instrumentation. Clin Infect Dis 24 : 558-561, 1997

21. Picada R, Winter RB, Lonstein JE, Denis F, Pinto MR, Smith MD, et al. : Postoperative deep wound infection in adults after posterior lumbosacral spine fusion with instrumentation: incidence and management. J Spinal Disord $13: 42-45,2000$

22. Plowman $\mathrm{R}$ : The socioeconomic burden of hospital acquired infection. Euro Surveill $5:$ 49-50, 2000

23. Watanabe M, Sakai D, Matsuyama D, Yamamoto Y, Sato M, Mochida J : Risk factors for surgical site infection following spine surgery: efficacy of intraoperative saline irrigation. J Neurosurg Spine 12 : 540-546, 
SSI after Spinal Surgery in Korea I Jeong TS, et al.

2010

24. Wimmer $C$, Gluch $H$, Franzreb $M$, Ogon $M$ : Predisposing factors for infection in spine surgery: a survey of 850 spinal procedures. J Spinal Disord 11 : 124-128, 1998

25. Wu PC, Kuo HK, Li M, Lai IC, Fang PC, Lin SA, et al. : Nosocomial postoperative endophthalmitis: a 14-year review. Graefes Arch Clin Exp
Ophthalmol 244 : 920-929, 2006

26. Ziebuhr W, Hennig S, Eckart M, Kränzler H, Batzilla C, Kozitskaya S : Nosocomial infections by Staphylococcus epidermidis: how a commensal bacterium turns into a pathogen. Int J Antimicrob Agents 28 Suppl 1 : S14-S20, 2006 